Article

\title{
From Uncertainties to Successful Start Ups: A Data Analytic Approach to Predict Success in Technological Entrepreneurship
}

\author{
Sarath Tomy * (1) and Eric Pardede (1) \\ Department of Computer Science and Information Technology, La Trobe University, Kingsbury Drive, Bundoora, \\ VIC 3083, Australia; E.Pardede@latrobe.edu.au \\ * Correspondence: s.tomy@latrobe.edu.au; Tel.: +61-470-105190
}

Received: 18 January 2018; Accepted: 19 February 2018; Published: 26 February 2018

\begin{abstract}
Understanding uncertainties and assessing the risks surrounding business opportunities is essential to support the success of sustainable entrepreneurial initiatives launched on a daily basis. The contribution of this study is the identification of uncertainties surrounding opportunities in the opportunity evaluation stage of the entrepreneurial process and the examination of how the analysis and evaluation of uncertainty factors, with the help of data, can predict the future success of an organization. In the first phase, the uncertainty factors are classified based on their sources and we discuss the likely implications towards new venture success with the help of existing literatures. In the second phase, a success prediction model is implemented using machine learning techniques and strategic analysis. The model is trained in such a way that, when new data emerges, the qualitative data is transformed into quantitative data and the probability of success or failure is calculated as the result output in the pre-start-up phase. The method and findings would be relevant for nascent entrepreneurs and researchers focusing on sustainable technology entrepreneurship.
\end{abstract}

Keywords: entrepreneurship; uncertainties; success prediction

\section{Introduction}

Historically, entrepreneurship research has been concentrated on entrepreneurs and their behaviors in creating new ventures. In recent years, researchers have shifted their attention towards the role of opportunities in the entrepreneurial process. Opportunities are chances that exist to meet a market need or interest through the creative combination of resources and capabilities to deliver superior value. Recognising an opportunity is an important step in the success of sustainable technology entrepreneurship [1,2]. Often, entrepreneurs seek answers to questions such as why, when, and how opportunities are created and why only some people discover these opportunities and how they exploit these entrepreneurial opportunities [3].

Small technology start-ups face intense time-pressure from the market and are exposed to tough competition, operating in a chaotic, rapidly evolving and uncertain context [4,5]. Despite many successful stories, self-destruction rather than competition drives the majority of small technology start-ups into failure within two years from their creation [6]. Many failures of new ventures are an outcome of the inability of the entrepreneurs to deal with uncertainties and bear the implications of the uncertainties. Uncertainties impinge upon almost all different stages of the entrepreneurial process, and the success or failure of firms depends upon how entrepreneurs deal with uncertainties before acting on an opportunity [7]. Uncertainties imply that the states, alternatives and preferences cannot be completely defined because of the lack of understanding about a situation $[8,9]$. Uncertainties may be a relative matter of subjective confidence about how the probabilities are estimated, or a case of a complete uncertainty where probabilities or outcomes are completely undefined [10]. Entrepreneurs 
involved in creating technology start-ups must deal with many uncertainties. Therefore, it becomes very important to study how the uncertainties and entrepreneurial intentions are related [11,12].

The environment poses both opportunities as well as threats for new venture creation [9]. In comparison with other sectors, the technology sector grows much more quickly. Thus, it is important to keep pace with technology in order to sidestep threats and grasp opportunities [13,14]. The degree of stability in the market is inversely proportional to the uncertainties in the market, and these uncertainties increase the probability of failure. Understanding the uncertainties and assessing the risks as well as the opportunities is essential to support the number of small business launched on daily basis [14]. A key part of the entrepreneurial plan is to identify the uncertainties surrounding an opportunity.

Nascent entrepreneurs face high degrees of uncertainty, and this needs to be addressed in order to recognize and exploit opportunities [15]. Without uncertainties, the projected business environment can be known perfectly, which improves the confidence of entrepreneurs $[9,16]$. According to Meijer [17], uncertainties have a great influence on the innovation decisions and actions of entrepreneurs. Similarly, $\mathrm{O}^{\prime}$ Brien [18] mentions that "increased uncertainty in the entrepreneur's target industry will decrease the probability of entry". According to Zack [8], uncertainties can be managed and reduced by developing technical resources and capabilities to predict, infer, estimate, and learn. If the entrepreneur is able to evaluate the environment and assess potential changes, there will be a great chance to recognise viable opportunities [10].

Milliken [16] describes uncertainties as an individual's perceived inability to predict something accurately due to the lack of sufficient information; they can be categorised into state, effect, and response uncertainties. State uncertainties refer to the lack of knowledge about current conditions and the uncertainties about the nature of general changes in state in the relevant environment at a future time $[9,16]$. Effect uncertainties are concerned with uncertainty about the cause and effect or the impact of unknown actions. Response uncertainties refer to the lack of knowledge about the response of the market or other relevant parties to a performed action $[10,16]$.

Despite the rich literature in the opportunity evaluation process in entrepreneurship, only a few studies attempt to classify the uncertainties involved in early-stage entrepreneurship. Meijer [17] proposes that uncertainties can encompass political, technological, competitor, supplier, consumer and resource aspects. Brun et al. classify uncertainties into six dimensions, namely technological, political, market, reputation, organizational and resource uncertainty [19]. Hoskisson and Busenitz [10] viewed uncertainties from two orientations: external orientation, that consists of perceived market uncertainty; and internal orientation, which comprises firm capabilities and learning distance. Acknowledging the local nature of entrepreneurship, the impact of uncertainties in evaluating opportunities may differ across regions. Research shows that geographical locations, and socio-economic and cultural factors play a crucial role in the entrepreneurial activity in both developed and developing countries [20,21]. As the main motivation of the decision-maker is to reduce uncertainty, the consideration of different uncertainty factors with sufficient information can reduce uncertainties in the opportunity evaluation process [22,23]. Butler et al. [7] proposed an uncertainty absorption model focusing on the capacity of the entrepreneurs to absorb and bear uncertainties. Wallace [24] proposed a deterministic mathematical model in which sensitivity analysis is combined with parametric optimization to facilitate decision-making under uncertainty. De Koning and Muzyka [25] proposed a socio-cognitive framework of opportunity recognition by considering three cognitive activities: information gathering, thinking through talking and resource assessing through interaction with an extensive network of people. Kuechle et al. [22] conducted an experimental study to investigate the impact of prediction-based strategies and control-based strategies on the decision to undertake uncertain prospects and the extent to which this relationship is affected by the nature of the information received by the individual and found that control-based strategies are more likely to lead to the acceptance of uncertainty in the presence of favorable information and prediction-based strategies are more likely to lead in the presence of unfavorable information [26]. Erikson [27] proposed a conceptual framework 
by considering the general company success factors and factors driving success for companies. There exists a gap in the entrepreneurship literature between the understanding of uncertainties and how to use these uncertainty factors to evaluate an opportunity and predict success or failure in the pre-start-up phase. Our research bridges the gap by analyzing uncertainties and providing a practical application for opportunity evaluation. Moreover, there is little research on success prediction by evaluating uncertainties, even though it is widely accepted that an entrepreneur cannot act on the opportunity successfully until he addresses uncertainties surrounding the opportunity. In today's hostile and dynamic business environment, it is vital for nascent entrepreneurs to assess the market uncertainty factors which influences business success before making a decision [28].

Our goal is to find the factors contributing to uncertainties in sustainable technology entrepreneurship and classify them based on the sources of uncertainties which influence the entrepreneurial decision to act on an opportunity. Thus, in the first phase, we classify the uncertainty factors based on their sources and discuss the likely implications towards new venture success with the help of existing literature. In the second phase, a success prediction model is implemented using machine learning techniques and strategic analysis with the help of data. The model is trained in such a way that, when new data comes in, the qualitative data is transformed into quantitative data, and the probability of success or failure is calculated as the result output in the pre-start-up phase. The particular strength of this method is to evaluate the opportunity based on unrelated factors and identify the patterns by the exploration of relations between them.

\section{Methodology}

Entrepreneurial opportunity is a central concept within the entrepreneurship field [29]. There are four principal activities that take place before a new business is formed-opportunity identification, opportunity evaluation, opportunity refinement, and opportunity exploitation. Even though these activities can overlap, interact and sometimes be confounded with one another, the opportunity evaluation occurs several times during the entrepreneurial process [1]. Opportunity evaluation is a critical element of the entrepreneurial process. It is a long-term process concerned with investigating and assessing the external environment to understand the risks associated with the venture [30]. Dimov [31] argues that opportunities are simply creative ideas and the potential value of the idea needs to be evaluated through opportunity evaluation process. Once an opportunity is identified, it needs to go through the evaluation process before it can be refined and exploited. Opportunity evaluation helps entrepreneurs to think beyond the current frame of reference in order to identify all the future influences associated with the perceived opportunity and thereby reduce the fear to act on it [32]. A major challenge in sustainable technology entrepreneurship is to evaluate the business opportunities in the fast-moving innovative global market [14,33]. The main barrier restricting an execution on an identified opportunity is the uncertainty or the risk. We utilize uncertainties as a method to evaluate opportunities, because these are factors which have a heavy influence on the success and growth of a firm. The evaluation of opportunities based on these factors is important in making decisions, not only for the entrepreneurs, but also for the government and other agencies promoting entrepreneurship. The purpose of the study is practical and is conducted in order to examine how the analysis and evaluation of uncertainty factors with the help of data can predict the future of an organization success.

Entrepreneurs face extreme uncertainty about how different factors influence the existing businesses in their intended industry and how other businesses perform. For nascent entrepreneurs, market analysis is considered to be the best method to assess the attractiveness of a specific industry for the enterprise and to reduce uncertainties [34]. Based on the analysis, nascent entrepreneurs can identify which are the dominant factors influencing the success and growth and how these factors contribute to the profitability and success.

Our proposed methodology consists of two stages: (1) uncertainty classification and analysis; and (2) success prediction and strategic position. 


\subsection{Uncertainty Classification and Analysis}

In this section, we focus on the uncertainties in the opportunity evaluation stage of the entrepreneurial process, because this is the decision-making stage of the entrepreneurial process where the entrepreneur, after evaluating the strength of the perceived opportunity, decides whether to exploit or ignore an opportunity $[5,10,17]$.

The literature on uncertainties in the entrepreneurial process of technology entrepreneurship during the opportunity evaluation stage does not have a well-defined classification. Our methodology aims to improve the understanding of uncertainties in technology entrepreneurship by classifying the uncertainty factors based on their sources. To start our classification, we follow Meijer's [17] uncertainty classification, as it is more relevant to new technology based start-ups, and identify the factors based on those classification. The uncertainty factors from each source of uncertainties are believed to influence entrepreneurial decisions. The different sources of uncertainties in the opportunity evaluation stage of the entrepreneurial process are shown in Figure 1 and are explained in the following sub-sections.

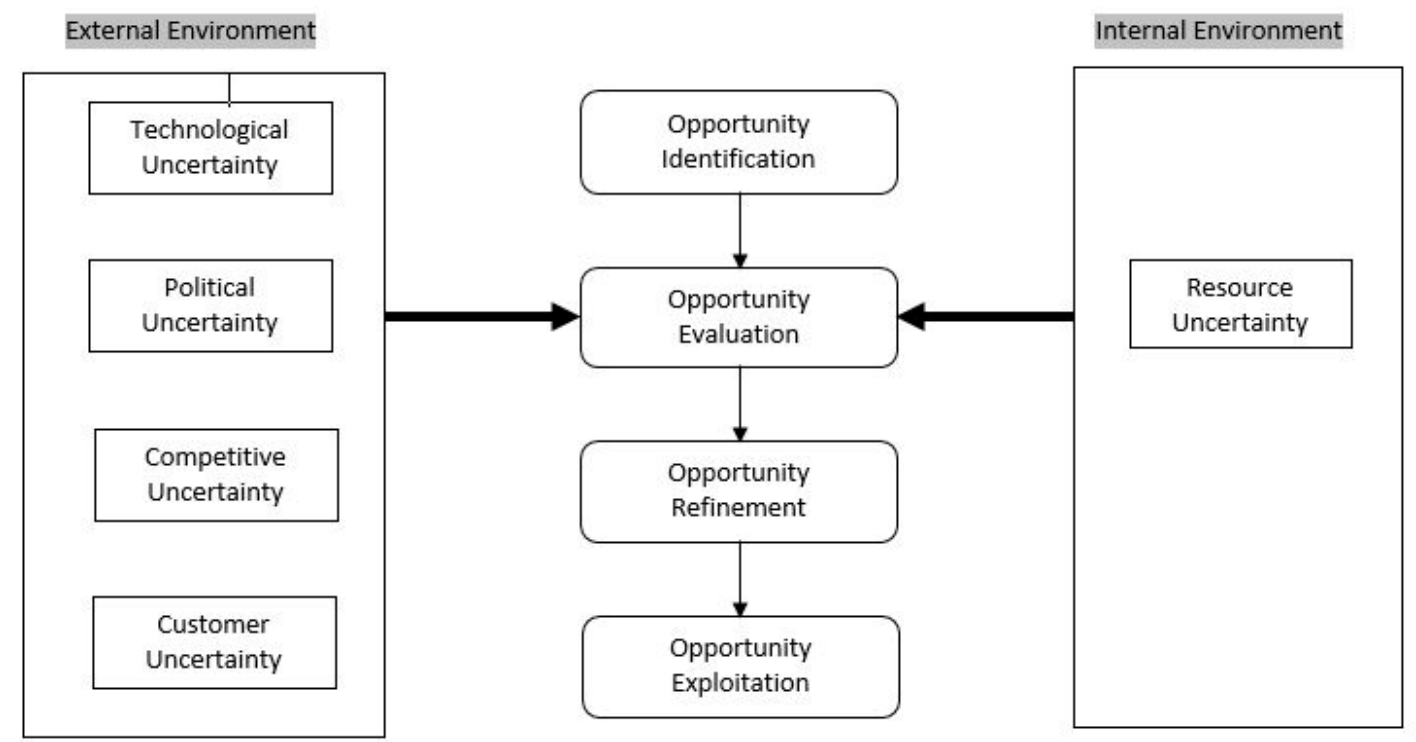

Figure 1. Uncertainties in the opportunity evaluation stage of the entrepreneurial process.

\subsubsection{Technological Uncertainty}

Technological uncertainty stems from the uncertainties about the technology itself, the technological system, the availability of alternative technological solutions and the characteristics of innovations [17]. According to Moriarity and Kosnik [35], technology uncertainty is higher where the technology is new or rapidly changing. Demand for new technologies and products are highly uncertain and innovations happen in the technology industry at breakneck speed. Therefore, technological uncertainty not only relates to the uncertainty about the availability of technological infrastructure and solutions but also relates to what extent adaptations need to be made to the current technologies as a result of future changes in the existing technologies and the introduction of new and improved technologies $[9,16,17,36]$. The more complex a technology is, the higher the technological uncertainty will be. Technology uncertainty refers to the questions about what can be expected of a new technology or innovation in terms of price, functionality and quality $[35,37]$. The technology uncertainty factors are described as follows.

\section{Technological Developments}

Technological developments include the availability of current technology and the adaptability of technological changes. Often, future technology change remains largely unknown, which makes it 
difficult to prepare for future opportunities $[2,10,16]$. Uncertainty is high during the early stages of technological development. It is important to attend to the effect of uncertainty on the development process, because the actions of technology developers and adopters mutually influence each other in the early phases of the technology life cycle [17]. The emergence of a technological standard can reduce the uncertainty [10]. Although a high degree of technological uncertainty regarding the emerging technologies provides many opportunities for that a new technology has to offer, these uncertainties possess the threat of not knowing what comes next in the technological path, which can determine the success or failure of a firm $[9,17,35,38,39]$.

Innovation Speed

Innovation speed is the time to market: the time taken from the initial development to the ultimate commercialization of products. A start-up's key to survival is the innovation in their first product and the ability to continue to innovate and bring their product to the market faster than competitors. Even though innovation speed is an important component for technology start-ups, a service-oriented venture can also survive on good customer relations, efficiency, and cost leadership [13,40]. Companies in a position of low uncertainty are likely to be in a position to pursue innovations associated with current technology [10]. As new products as well as services are being developed, unanticipated anomalies invariably emerge, and it is very difficult to predict the receptivity of a new invention or innovation once it is released to the market $[10,41]$.

Process and Methods

R\&D and knowledge development are prerequisites within an innovation system [42]. Process innovation methods follow a protocol to use techniques capable of developing new products, deliver quality, respond to customer needs, manage projects, and innovate. It is important to understand the time to market for products and services. Process and models include traditional, agile, test and quality approaches. This includes questions regarding the product development process, platform and applications, specialised competencies, developing time, and project management skills [13].

Technological Infrastructure

The standard of technological infrastructure, such as telecommunication networks and internet technologies along with physical infrastructure, has a direct impact on the ability of the business in managing customers [27]. Availability of physical infrastructure and utilities are crucial in entrepreneurship. Access to suitable resources increases the chance to start a new venture [18]. Even though the requirement of technological infrastructure is relatively low and easily available for software ventures in comparison with other industries, it is also an important factor of evaluation because of the limited time to respond to customer needs.

\subsubsection{Political Uncertainty}

Political uncertainty refers to the uncertainty about governmental behavior, regimes, and policies or future change in policies. Political factors are crucial for entrepreneurial success as the government plays the role as a planner, promoter, and regulator of business firms [40]. Political decisions can impact on many important areas of business especially in terms of direct and indirect taxes, employment laws, consumer protection laws, trade restriction or reforms, safety regulations, philosophy of political parties, political power, and stability of the operating region, sales or corporate headquarters. Uncertainties in business regulations, taxation, contradiction between local and national government regulations, trade union policies, personal privacy, copyrights, intellectual property, distribution and electronic contracts can have serious impact on the decision to start a new venture $[5,16,17,36]$. We present the main political uncertainty factors in detail as follows. 


\section{Political Environment}

Unstable or polluted political conditions, where a government changes its policies frequently, lead to uncertainty which discourages entrepreneurs to act on an opportunity. Therefore, the stability in the political environment influences uncertainty and thus influences the development of entrepreneurship [10]. Misra et al. [43] suggest that an entrepreneur in a country with fewer obstacles to launch a new business will help to start his venture within less time. Entrepreneurial growth in a country depends on the political ideology of government in making favorable policies which encourage new venture creation [41,43]. This factor also includes government policy, such as the degree of intervention in the economy, which affects a firm's ability to be profitable and successful. Understanding the varying laws and regulations in a given region of operation is critical to avoiding unnecessary legal costs $[16,17,36]$. Political environment analysis includes global and international issues, trade barriers and tariffs, trade agreements, waiting time, legal structures and licensing [17,43]. The availability of external investment capital is one success factor of businesses, especially in their early stages. The level of demand within the economy is directly impacted because of the public spending by central and local government [27].

\section{Government Support}

Government support in the mode of potential subsidies and research grants can affect the rate, timing, and substance of an innovation of business [17,36]. Even though government support in the form of economic development through infrastructure development, information technology parks and incubators, flow of knowledge from public research to the productive sector through open data access, conferences, workshops, and research collaborations devoted to a specific technology topic are available in most places, most often entrepreneurs are uncertain about how to access these services [42].

Legal Procedure

Procedures to register and operate a business can influence entrepreneurship directly and indirectly. The regulations for new venture creation include a number of procedures, time, and cost [43]. Lack of formal institutional structure, extensive number of rules and regulations, requirement of detailed documentation and reports often create uncertainty and delay the venture start-up, because it requires entrepreneur's continuing effort and time [13,43].

\section{Inflation and Exchange Rates}

A low inflation rate provides a favorable environment for new venture creation. On the other hand, high inflation rates often increase the uncertainty about the future and restrict the financial institutions to allocate resources to new ventures. They also have great influence on interest rates and exchange rates $[9,43,44]$.

\section{Employment Laws}

The application of labor and labor-related laws in the intended operating region can have a significant impact on entrepreneurship, especially in developed countries. Even though these laws are important means of improving job quality, promoting decent work, broader economic development and growth, rigid labor protection laws are often perceived by entrepreneurs as imposing unsustainable regulatory burden and costs [43,45]. Moreover, the setting of wages according to the industry standards may not be affordable to most start-ups, especially when they need to compete with larger companies who are outsourcing many of their information technology jobs to developing countries where labor is cheap $[46,47]$. 
Taxation

Consumer spending and market demand are influenced by direct and indirect taxes. Corporate taxation has an impact on the profitability of businesses. High taxation leads more companies to outsource their service and investors lowering their risk by reducing investments [27]. High taxes that cut the capital gains and success usually discourage entrepreneurs. On the other hand, lower taxation fosters investments, generates employment opportunities and economic growth [43]. Moreover, entrepreneurs with taxation concerns may take a longer time to plan and thus increase the new venture creation time [42].

\section{Economy}

Since the information technology market is a global market, global economic trends can have a great influence in technology entrepreneurship. There is extensive evidence that economic factors play an important role in an entrepreneur's entry decision, and they exploit opportunities that have greater expected values. Thus, entrepreneurial entry is more when there is high industry profit margins and more demand [18]. Research shows that entrepreneurial entry is more when there is high economic growth, lower unemployment and less capital is needed [3,18]. Economic factors are metrics that measure and assess the health of the country's economy in which the business operate $[18,43]$. During the recession which happened in 2008-2009, the most affected industry was finance and IT, and many companies shut down, resulting in a high unemployment rate. Thus, global economic consideration is important in opportunity evaluation, especially in an uncertain context, to predict whether the targeted businesses are entering a booming economy [43].

\subsubsection{Competitive Uncertainty}

Competitive uncertainty refers to the lack of awareness about the competition's actions and behavior in the rapidly-evolving market. It includes the inability to identify the competitors, their product and service offerings and the strategies they use to compete [16,36,37]. New firms are at a high risk of failure in comparison with existing firms because of the limited availability of resources and a lack of established channels with suppliers and customers. Thus, it is important for new firms to understand the competitive market in a way to react to actions of the competitors in a timely way with improved product and services [44]. We present competitive uncertainty factors in detail as follows.

\section{Competitive Environment}

Number, relative size and diversity of competitors determines the market opportunity [13]. Many uncertainties exist in entrepreneurial activities in the context of rapidly changing environments and hyper competition. Therefore, faster learning that builds on firm-specific knowledge and action is necessary [10]. If technology remains unchanged over a long time, the way competitors respond in the market is fairly stable. However, the technology is changing quickly in the IT sector, resulting in new competitors and aggressive actions of existing competitors, which is creating unstable markets [10]. Some firms open the door for substantial learning and staging for the evolving changes, while other competitors will be under-prepared for the market changes [10]. The ability to concentrate on and develop core competences makes a business successful. Core competences are a set of abilities, skills, knowledge, and expertise possessed by a business over its competitors, and they are the driving forces of a firm's competitive strategy and competitive advantage. A software firm is always in competition with other software firms because of their easier access into the international market. Apple, Microsoft and Google survive in overlapping markets where their products partly compete for customers. The value of their products and services are partly determined by how they compete in the market which provides them a sustained competitive advantage. As long as the environment is competitive, uncertainty exists in its peak [13]. 


\section{Type of Competition}

Every business has competition, and this is especially true in the IT sector, even though not all competition is bad [48]. Direct competition exists when other competitors offer the same products and services and are trying to reach the same market. Indirect competitors are those who are providing different products and services but targeting the same market. At many times, the indirect competitors help in creating opportunities. Since they are targeting the same market with different products and services, there is a possibility of related products or service as well. Thus, the more indirect competitors in the target market, the more opportunities exist. The relative price, quality, and switching costs determine the power of competition [13,48]. Shi et al. [44] stressed the first-mover advantage, which is essential for start-ups; they need to respond in a timely way to the market needs and learning capability, integration capability, and responsiveness capability is crucial.

\section{Leading Competitor}

Competitive ratings of primary and secondary competitors give valuable insight into the industry, product or service offerings, changes in sales and customers. To maintain industry leadership, some firms invest largely in sustaining their current technologies and core capabilities, and most of these firms find it hard to embrace emerging innovative technologies due to their high cost and entrepreneurial energy. Some competitors have a difficulty in "envisioning" the potential of the new technology, because it changes the base of competition and competence of the incumbent leader $[10,49]$. Sometimes the re-creation or modification of a firm's original concept, product or idea with improved technological innovation can lead to great success [50].

\section{Share of Market}

Most innovative companies are based on one or more products where they hold a market [13]. Reputation and recognition of the company helps to attract customers [50]. Usually, start-up firms are more uncertain than that of existing companies with an established track record of financial performance and market sales [35]. Even though the windows of opportunity are smaller in the IT sector, the rapid evolutionary growth of the IT industry provides greater frequencies of opportunities [50]. However, the entrepreneurs need to exploit the opportunities before competitors. If the main market is held by only a few companies, it is difficult to exploit an opportunity. However, many competitors provide an uncertain environment where start-ups can benefit from their products and services. First-mover innovation is important as it helps to get monopoly advantages to increase the potential market share because of rivals' lagged responses [17,44,51].

\section{Marketing Strategy}

Business planning and marketing support are critical for the successful growth of a firm. In addition, understanding the competitors and their marketing strategies also needs careful consideration [49]. Often, an entrepreneur is uncertain about how to reach customer segments. Skinner [50] conducted investigations of ten successful ICT innovations and he found an increasing trend towards social networking as one important success factor. Even though partnership and alliances help to create distribution channels for the products as well as services, new ventures are always confused about which ones work best or which ones are most cost-efficient [13]. Uncertainty in formulating a competitive strategy in order to compete with other competitors with substitute products can affect the business in the first stage [35].

\subsubsection{Customer Uncertainty}

Customer uncertainty refers to the lack of knowledge about user acceptance and demand with respect to the new technology. It includes uncertainty about some macro-economic developments such as population growth, customer's characteristics, adoption rates, potential market size, purchasing 
power of potential customers, market growth and their long-term development of the demand over time. $[5,16,36]$. For innovative products, there will be high uncertainty about the customer expectations regarding a product, its characteristics, whether it fulfils the customer needs and preferences, quality, prices, and appropriate distribution channels. In order to exploit an opportunity, an entrepreneur should understand the specific aspects of user needs [52]. The factors associated with customer uncertainty are described below.

\section{Potential Market Size}

Failure to evaluate the potential market size is one of the top reasons for the failure of start-ups [53]. Uncertainties about the volume and value of potential market size act as a barrier to bringing an idea to market. If the market size is massive, the opportunities are high, while if it is a small niche, there will be limited opportunity [54]. Sometimes, the location can have an impact on the market size. For example, the USA stands as an ideal place for ICT entrepreneurship because of the opportunistic market and large market for information technology products and innovations [50].

\section{Segmentation}

Segmentation is important in understanding who our most important customers are and for whom we are creating value, and whether they are clustered or monopolised. Demographic changes such as population, migration, age, structure, living conditions, employment status, education, income, social trends and values, social and cultural shifts can have a heavy influence on the demand of products and services as well as the buying power of customers. Even though many of them are unpredictable without published data, opportunities can be found if the entrepreneur observes the changes in the external environment $[9,13,54]$ According to Dollinger [9], "Changes in the social values and customer tastes, as well as demographics shift the economics of industries to a new equilibrium. The markets of firms that do not adapt to these changes are fair game for the entrepreneur".

\section{Living Conditions}

The speed of social, culture and demographic change can be expected to increase because of the improvements in communication and increased employee mobility between countries. Social factors that have impacts on the market include demographic analysis, such as population growth rate, age distribution, unemployment rates, overall education levels of the population, willingness of individuals to work or start business, job market trends, workforce immigration, cultural and social conventions, living conditions, life style changes, adoption of new technologies and services, acceptance and growth of e-commerce, provision of medical and financial services remotely, attitude towards health, career and environmental issues $[40,43]$. These factors do not only have impacts on the functioning of a business but also influence the ability of a firm to obtain resources, identify the opportunities and threats, and market its products and services [40].

\section{Customer Needs}

Understanding the customer needs is a crucial part of entrepreneurship and unfulfilled customer needs provide opportunity to the specific market. Rose [13] argues that the success of a company depends on the ability to recognise the customer problems and unfulfilled needs and offer products and services to each customer segment. Customer needs change day by day and new products and services are emerging fast $[9,55]$. It is difficult to foresee the future markets to evaluate the potential value of the opportunity [54]. The entrepreneur needs to stay informed about the changes and fulfil their customer's needs over time to maintain its competitive advantage [49]. 
Purchasing Power of Potential Customers

According to Wenzel [49], "a successful business provides valued products and services to customers at a price they are willing and able to pay". Thus, the entrepreneur needs to understand how much the customer is willing to pay or how much the competitors are charging. The number of potential customers relative to companies offering the same product or service also determines the purchasing power. The switching costs to use other products or service or use of multiple services, quantity and frequency of purchase all depend on the customers' purchasing power [5,13,49]. In certain circumstances, people must not agree on the value of product or service, which causes uncertainty in the pricing strategy [54].

Purchase Behaviour

Customers hold different perceptions of the same reality, and these differences affect their demand and spending on products and services. The purchase behavior can be impulsive or carefully considered [9]. Ongoing products and services are the backbone of technology entrepreneurship. Many companies depend on long term projects to sustain. Thus, it is important to have an idea whether the product or service offering is sustainable or not. Understanding the market and remaining flexible to the customer's changing needs can only lead to long-lasting business success. The key to the success of a venture is to "fulfil customers' needs in a way that keeps attracting new customers and keeps existing customers coming back." [49].

\section{Alliances}

Entrepreneurial opportunity often demands the seeking of partnership arrangements which help to bring together the skills and firm specific resources in order to complete partial capabilities need to realize the perceived opportunity [10]. New partnerships create further resources and new goals. The need to complement scientific brains with entrepreneurial and business ones is important because there are many evidences that these technical and commercial partnership actions help small technology ventures to achieve business success [56]. Even though interaction with potential partners and co-operating with them to develop products and competencies can boost business, it is difficult to make alliances in the early start-up stage [13].

\subsubsection{Resource Uncertainty}

Resource uncertainty refers to the uncertainty about the availability of financial resources and skilled human resources. Resource uncertainty is caused by the difficulty of making accurate forecasts of the resources and the capital investments that are needed for the innovation projects and innovation process such as the availability of knowledge and skills, availability of expertise, in-house and external R\&D expenditures, offices, machines, technology adoption, technology transfer, educating personnel, revenue streams, and cost structure $[5,16,17,36]$. Questions arise regarding which kind and what quantity of key resources and activities are necessary to develop in order to execute the business; what the operating expenses will be; which resources and activities are most expensive; whether to search for key potential partners ; what channels need to be used; how costly they are; how to generate income; how much the customer pays; how they currently pay; how they prefer to pay; whether the cost is less than revenue; when the business will be profitable and so on [13,57].

As the opportunities vary over time, the resources necessary to exploit those opportunities need to be identified by analysing the market environment. Therefore, managing resources strategically needs continuous evaluation [51]. If the resource has the ability to bring value by enabling a firm to exploit opportunities or neutralize threats in the environment, it is valuable. It is important to note that since the constantly changing external and internal conditions can make the resources less valuable or useless, it is necessary to continually review the value of resources. If the sources, activities or process do not add any advantage or economic value, it is an economic disadvantage [30]. 
Entrepreneur's Education and Experience

The role that individuals play in sustainable technology entrepreneurship is undeniable. Each person's psychological, sociological, and demographic characteristics contribute to or detract from his or her abilities to be an entrepreneur. Personal experience, knowledge, education, and training are the accumulated human resources that the founder contributes to the enterprise [9]. Entrepreneurs work experience is a decisive factor to influence their potential success, and there are many works cited earlier proposing an entrepreneur's education, prior knowledge, training and work experience as key factors in the opportunity recognition process $[2,27,56,58,59]$. Shane [60] argues that the ability of an entrepreneur to recognise the value of a particular technological innovation to utilise the market opportunity is based on his previous work experience in dealing with similar situations.

\section{Social Networks}

Social networks are an entrepreneur's personal resources and networking. Most of the time, the entrepreneur is not alone and relies on a network of other people, other business people and other entrepreneurs to acquire additional resources to start his venture. "Who you know" and "who knows you" are important and valuable resources in new venture creation. This gives the entrepreneur access to resources without controlling them and thus reduces the potential risk of ownership and keeps overhead down [9]. Both internal and external social capital facilitates exploitation of entrepreneurial opportunities [51].

\section{Capital}

Capital is an important factor which allows the entrepreneur to bring together other factors and use them to produce goods or services $[9,13]$. Often, new firms rely on the entrepreneur's financial resources, since funds are not readily available from other external financial sources such as banks [27]. Entrepreneurs having stronger ties to resource providers that can generate capital are more likely to exploit entrepreneurial opportunities [18]. The availability of capital and incentives in the market influences sustainable technology entrepreneurship initiatives. Along with external finance options such as domestic credit provided by banks, the availability of cost-effective borrowing opportunities such as from angel investors plays a critical role in promoting entrepreneurial ventures [43].

\section{Skilled Human Resources}

According to Koc [61], the depth and variety of skills and experiences of the employees are considered as an important element of successful innovations by the software companies examined. In technology-based firms, it is always a question regarding who the actors are, how knowledge is transferred and which role the different parties need to play to exploit opportunities [41]. Even though the entrepreneur is the driver and leader of the venture, it is true that no business succeeds without skilled and committed workforce. Finding the right kind of skills-education, training and experience-is challenging for ventures that are highly innovative and exploiting new technologies, but it has a major impact on project performance, cost and cycle time, which is crucial for new ventures to get into the market within the limited time [27]. A software firm requires the functional specialists to work on issues such as technical programming, configuration management, quality assurance, technical writing, systems engineering, hardware engineering, and is made up of people who have high quality skills and talents in specific field such as programmers, developers, project managers, architects, customer relations, sales personnel all need to work as a team $[9,13,43,61]$.

\section{Technological Resources}

Technological resources and access to new innovative technologies are crucial in sustainable technological entrepreneurship. Technical resources are physical, intangible or legal entities which consist of process, systems and physical transformations. It includes labs, R\&D facilities, testing and 
quality assurance technologies $[9,56]$. In most cases, the entrepreneur need to think of how to take advantage from open source software and the open source development model [13].

Innovation Process

Technology itself is not an innovation, and it requires the necessary knowledge to exploit it into a profitable opportunity by combining the technology with market needs [56]. The understanding of designing and improvement practices in developing innovative software solutions for a new firm is important to get into the market [13]. Shane [60] demonstrates that just one technology can create multiple business opportunities by surveying eight entrepreneurs who all exploited very different market opportunities using one original technology patent.

\section{Intellectual Property Rights}

According to Dollinger [9], new knowledge and innovations are superstars of entrepreneurial opportunity. However, having knowledge is not enough. The entrepreneur needs to find an avenue to make products out of it and hold the intellectual property as secured as possible to keep it away from the competitors copying it or protect the profits of those products from competition as the knowledge is spread to others [9]. Knowledge generated by research and development protected by patents is a resource. Therefore, knowledge is a type of intellectual property in the form of formulas, licences, trademarks, and copyrights $[9,56]$. The entrepreneur needs to have an understanding of the intellectual property situation-for example, patents, copyrights, open source codes in the related areas-as these act as barriers of entry for new ventures [49]. Giarratana [52] demonstrates how patent security in the encryption industry leads to two income sources from off-the-rack software products and from authorizing the license to other software organizations. Software not secured by copyright can be unreservedly duplicated, which decreases its quality for its developers. Business can limit competition to some extent by seeking patents and copyrights [13,49].

\section{R\&D Expenditures}

Resources are limited during the early stages of venture creation. However, more investment is needed in the R\&D process in searching for breakthrough ideas even though the entrepreneurs have only a little information and knowledge about possible investment outcomes. Thus, they face higher levels of investment uncertainty on the return on investment [10,12,42]. Entrepreneurs will face higher levels of investment uncertainty when they have little information and knowledge about possible investment outcomes.

\section{Operating Expenses}

Managing a company is very different to starting and operating it. It is also a leadership and management challenge at most times, as customers are uncertain on how they manage the expenses. Maintenance costs in the form of office rent, bills, employee wages, machines, products, market research, promotions and advertisement, and other services need to be considered before starting the entrepreneur journey $[13,18]$.

\section{Revenue Streams}

New entrants are concerned about how and when they can generate revenue and profit and are uncertain about the potential income streams. One of the main reasons of the failure of start-ups is because they go out of business before sufficient revenue comes in [62]. The fundamental job of entrepreneurs is to create value from the opportunity, and this value can be generated from products, services, licenses, patents and so on [13].

Uncertainty classification is an initial screening mechanism to assist entrepreneurs to better understand the influence and nature of uncertainties surrounding an opportunity which can have 
impact on the sales, profit, innovation power and growth of the business. Table 1 lists a summary of uncertainty factors derived from the literature corresponding to each type of uncertainty which exists in the internal and external environment which are important to the creation and growth of entrepreneurial ventures. The approach we used aims to identify and categorise the factors by mapping the factors with respect to each types of uncertainty from existing literatures. Analysing the environment is the safest method to reduce the level of uncertainties, because the entrepreneur needs to think beyond the current frame of reference in order to identify all the future influences on the business and thereby reduce the fear to act on an opportunity [32]. The success prediction methodology for estimating the strength of opportunity in face of these different types of uncertainties is described in the following section.

Table 1. Classification of uncertainty factors of business opportunities.

\begin{tabular}{|c|c|c|}
\hline Uncertainties & Uncertainty Factors & References \\
\hline \multirow{4}{*}{ Technological uncertainty } & Technological developments & {$[2,9,10,16,17,35,38,39,56]$} \\
\hline & Innovation speed & {$[10,13,18,39-41]$} \\
\hline & Process and methods & {$[13,42]$} \\
\hline & Technological infrastructure & {$[10,18,27,63]$} \\
\hline \multirow{7}{*}{ Political uncertainty } & Political environment & {$[9,10,16,17,27,36,43]$} \\
\hline & Government support & {$[17,32,36,42,50]$} \\
\hline & Legal procedure & {$[13,43]$} \\
\hline & Inflation and exchange rates & {$[9,13,43]$} \\
\hline & Employment laws & {$[45-47]$} \\
\hline & Taxation & {$[27,42,43]$} \\
\hline & Economy & {$[3,18,40,43]$} \\
\hline \multirow{5}{*}{ Competitive uncertainty } & Competitive environment & {$[10,13,32]$} \\
\hline & Type of competition & {$[13,44,48]$} \\
\hline & Leading competitor & {$[10,49,50]$} \\
\hline & Share of market & {$[13,17,35,44,50,51]$} \\
\hline & Marketing strategy & {$[13,35,49,50]$} \\
\hline \multirow{7}{*}{ Customer uncertainty } & Potential market size & {$[27,50,53,54,64]$} \\
\hline & Segmentation & {$[9,13,54]$} \\
\hline & Living conditions & {$[43,44,64]$} \\
\hline & Customer needs & {$[9,13,32,49,63,65]$} \\
\hline & Purchasing power of potential customers & {$[5,13,49,54,64]$} \\
\hline & Purchase behaviour & {$[9,13,49,57]$} \\
\hline & Alliances & {$[10,13,56]$} \\
\hline \multirow{10}{*}{ Resource uncertainty } & Entrepreneur's education \& experience & {$[2,27,56,58-60,64]$} \\
\hline & Social networks & {$[9,51,63]$} \\
\hline & Capital & {$[9,13,18,27,43,63]$} \\
\hline & Skilled human resources & {$[9,13,27,41,61]$} \\
\hline & Technological resources & {$[9,13,56,63]$} \\
\hline & Innovation process & {$[13,56,60,61,63]$} \\
\hline & Intellectual property rights & {$[9,13,49,52,56]$} \\
\hline & R\&D expenditures & {$[10,42,63]$} \\
\hline & Operating expenses & {$[13,18,49,63]$} \\
\hline & Revenue streams & {$[13,18,62]$} \\
\hline
\end{tabular}

\subsection{Success Prediction Model}

The success prediction model shown in Figure 2 utilizes the uncertainty factors in order to evaluate the opportunity and predict the probability of success based on the existing dataset. Here we employ data analytics and machine learning techniques to predict a firm's success. The model is used to uncover the frequency of the relations that links the input uncertainty factors with the success or failure of a firm. Analyzing the data of other companies can help to make experience-based decisions. Decision-makers commonly use this information to drive their choices. Entrepreneurs can 
learn, analyze and evaluate the business success from the data of existing businesses in a particular region. Here, we try to predict the success of an opportunity by analyzing the uncertainty factors as shown in the Figure 2. This allows nascent entrepreneurs to make likelihood predictions on the basis of relevant datasets. The model consists of four main sections: data analysis, situation analysis, business rules and the predictor.

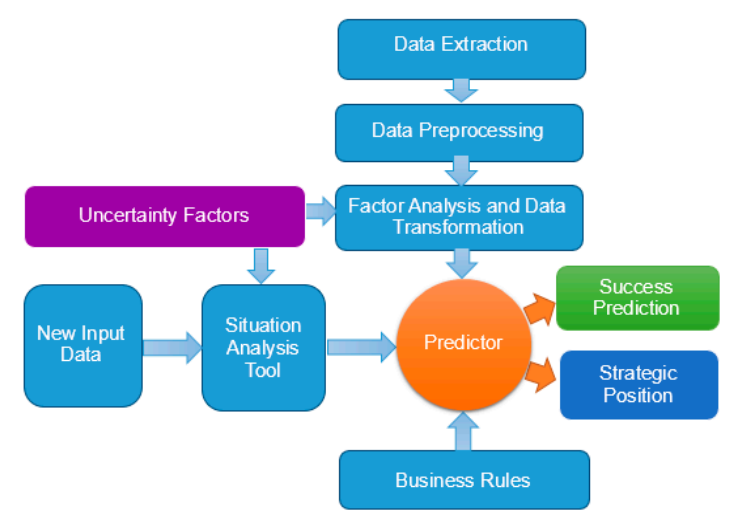

Figure 2. Success prediction model.

Data analysis is the process of exploring and inspecting data in order to extract useful information. Data analysis consists of four steps. Identifying and extracting the data sets of a specific domain is the first step. Data pre-processing is the next step, where the cleaning of the data to make it in the appropriate format occurs. Then, the data after pre-processing is mapped to the uncertainty factors identified in the literature. The qualitative data is converted into quantitative data before being fed into predictor. The situation analysis interface is an interactive graphical user interface that provides access to select the range of each uncertainty factor to quantify the opportunity based on the ratings and weights given to each factor, where the domain expert can evaluate the environment. This strategic interface is as a web interface where the factors are arranged in each category with text boxes next to each attribute for the domain expert to rate from 1 to 4 according to the options next to each factor as shown in Figure 3 . The business rules consist of a specific set of rules to calculate the dynamism of uncertainty factors in calculating the success; for example, if the values for all uncertainty factors are not available, then the rule can be set to use only uncertainty factors or use all factors by using default weightage when calculating the strategic position. The predictor is the heart of this model, where all the mathematical calculations takes place. The predictor gives two outputs-success prediction and strategic position.

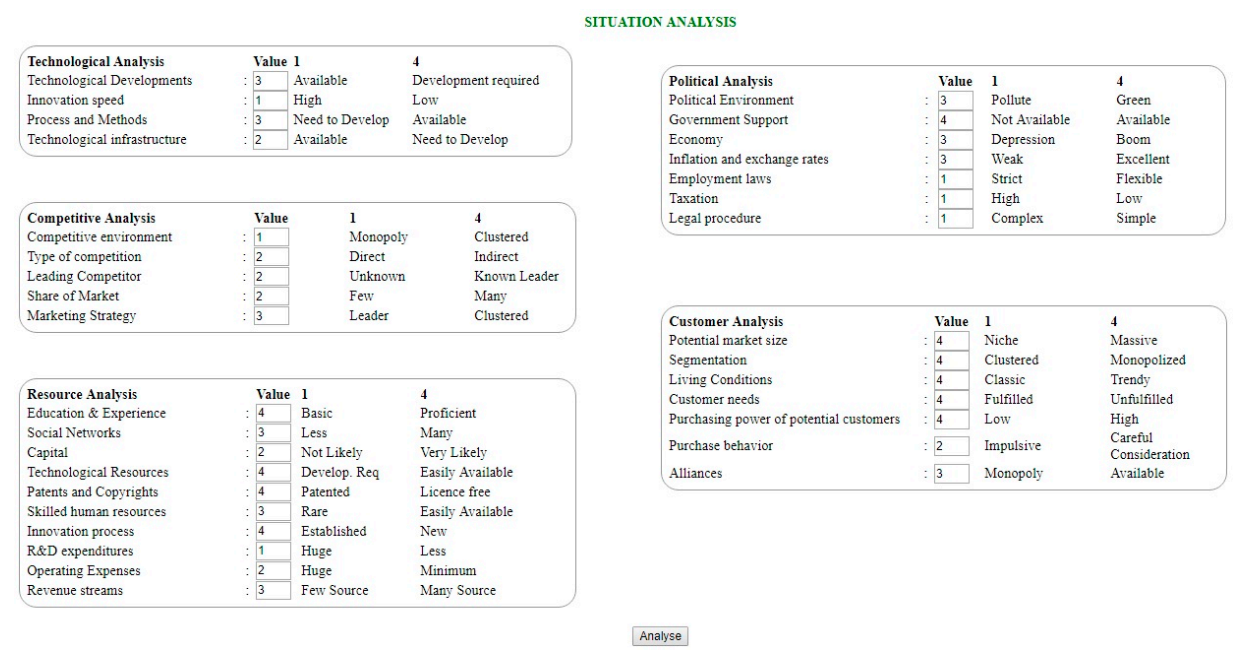

Figure 3. Situation analysis interface. 


\subsubsection{Success Prediction}

The success prediction system is trained by giving an input based on the classified uncertainties. The approach here is to apply a machine learning algorithm to train the model, and the prediction of the success or failure depends on the input values. At the beginning, the filtered dataset is fed into the predictor to train the model with this dataset. As our explanatory factors are categorical and independent, the predictor in our model is built using a supervised classification machine learning algorithm as a statistical tool to manage uncertainty and predict the success. The success prediction system is trained by giving inputs based on the classified uncertainties. In order to choose the best machine learning algorithm, the accuracy of three main widely used classification algorithms in the area of machine learning applications for probabilistic induction, including naïve Bayes, k-NN (k-nearest neighbours) and SVM (support vector machine), is compared and identified. Naïve Bayes has a higher accuracy than the other two [66]. The naïve Bayes classification algorithm is a classification algorithm based on Bayes rule with conditional independence assumptions $[67,68]$. Once the "predictor" is constructed by using the training data, whenever a new data comes in, the qualitative data is transformed into quantitative data and the probability of success or failure is calculated as the result output. It computes the maximum likelihood of success or failure based on the training data distribution and predict the output accordingly.

\subsubsection{Strategic Position}

To find the strategic position using uncertainty factors, we use the EFE (external factor evaluation) and IFE (internal factor evaluation) matrix evaluation methods that have been extensively used in the literature to evaluate firm performance [13,69-75]. EFE matrix is a strategic tool to analyse the external environment, while IFE matrix examines the internal environment [69,74]. Even though these tools are not widely used in the field of sustainable entrepreneurship, they are critical tools for evaluating the strength of an opportunity by prioritizing and ranking the key external and internal factors. Moreover, these matrices provide valuable insights beyond opportunity evaluation to help the entrepreneur plan his venture's future [70,74].

The EFE matrix factors consist of factors derived from the technological, political, competitive and customer uncertainties while the key factors derived from the resource uncertainty forms the IFE matrix [76]. The factors are given weights $w_{i}$ depending on their relevance in determining the success. Even though there is no "best" method factor weighting in sustainable entrepreneurship, researchers used a wide variety of methods for eliciting weights $[3,7,24,38]$. Here, the factor weights are calculated using a relevant dataset and determined by the level of importance they constitute in determining the success of the firm. In order to calculate the weightage, firstly the factor relevance score of each factor is calculated based on the factor frequency as shown in Equation (1).

The factor relevance score for a factor $i$ is

$$
s_{i=\frac{n_{s}}{N}}
$$

where $n_{s}$ is the number of positive records constitute to firm success and $N$ is the total number of records having factor $i$.

The factor weights are calculated using EFE and IFE matrix evaluation methods. The sum of all assigned factor weights in EFE as well as IFE matrices must be equal to $1[74,77]$. So the external factors and internal factors are given weights based on their relative importance with other factors using the factor relevance score $s_{i}$ as shown in Equation (2).

$$
w_{i}=\frac{s_{i}}{\sum_{i=1}^{n} s_{i}}
$$

The factor weights $w_{i}$ can vary quite a bit, but the weights are in the range between 0 and 1 depending on the relative importance. Zero means the factor is not important, and 1 means the factor 
is the most influential or critical one. The values of each factor from the situation analysis interface are multiplied with its weight to find the weighted score for the factors as shown in Equation (3).

$$
W_{e}=w_{i} \times r_{i}
$$

where $w_{i}$ is the weight of factor $i$ and $r_{i}$ is the rating given by the domain expert for that factor via situation analysis interface.

Finally, in order to find the strategic position, total weighted scores from the EFE and IFE matrices are plotted as the internal-external matrix (I-E), in which the EFE matrix value is displayed on vertical axis and IFE matrix value is displayed in the horizontal axis. The meeting point of both the axis value of the position of the opportunity with the current external and internal analysis. According to the matrix evaluation methods, a total score of 2.5 is an average score based on a 1-4 rating. In EFE, a total weighted score falls below 2.5 consider as weak while above 2.5 consider as strong in position [69,72]. If $y$-axis and $x$-axis values shown in the graph are between 1 and 2.5 , this represents an external threat and internal weakness, respectively, while values between 2.5 and 4 indicate an opportunity and internal strength, respectively. A low total score means the opportunity does not exist or that the chance of success is rare. [72].

\section{Implementation and Dataset}

The prediction model is implemented as a web interface using HTML, PHP, and JavaScript with MySQL database. The search for the datasets which can map the uncertainty factors with the firm performance lead us to the use the 2013 Victorian ICT Industry Statistics survey conducted by the Government of Victoria in Australia with 265 ICT companies as the participants as the primary dataset [78]. We select this data set because of two reasons. Firstly, the dataset measures the factors that can be matched with the uncertainty factors identified in our model. Secondly, the dataset is a survey conducted by a government body for technology companies, which is the industry focus of our research. After cleaning and filtering, a final dataset consists of 248 records was used in this study and the success is measured in terms of firm's profitability. The survey contains of questions regarding the companies' products and services, export regions, total revenue and so on. However, for our purpose we are only interested in how the external market factors influence the company's success and failure.

In the first step of the uncertainty analysis stage, we extract the factors, such as Domestic Economic Environment, Global Economic Environment, Government Regulation, Access to Finance, Exchange Rates, Competitive Environment, Access to Export Market, Availability of Skilled Employees, Access to Target Market, Availability of Infrastructure, Innovative Environment and Cost of R\&D from the ICT survey dataset. In the second step, the uncertainty factors identified from the literatures were matched and grouped with respect to the factors identified from the data and then categorized it as shown in Table 2.

Table 2. Mapping of uncertainty factors from data.

\begin{tabular}{ccc}
\hline Uncertainties & Uncertainty Factors-From Data & Uncertainty Factors-From Literature \\
\hline \multirow{2}{*}{ Technological uncertainty } & Innovative environment & $\begin{array}{c}\text { Technological developments } \\
\text { Innovation speed } \\
\text { Process and methods }\end{array}$ \\
\cline { 2 - 3 } & Availability of infrastructure & Technological infrastructure \\
\hline Political uncertainty & Domestic economic environment & $\begin{array}{c}\text { Political environment } \\
\text { Government support } \\
\end{array}$ \\
\cline { 2 - 3 } & Exchange rates & Economy \\
\hline & Government regulation & Employment laws \\
& & Taxation \\
& & Legal procedure \\
\hline
\end{tabular}


Table 2. Cont.

\begin{tabular}{|c|c|c|}
\hline Uncertainties & Uncertainty Factors-From Data & Uncertainty Factors-From Literature \\
\hline \multirow[t]{2}{*}{ Competitive uncertainty } & Competitive environment & $\begin{array}{l}\text { Competitive environment } \\
\text { Type of competition } \\
\text { Leading competitor }\end{array}$ \\
\hline & Access to target market & $\begin{array}{c}\text { Share of market } \\
\text { Marketing strategy }\end{array}$ \\
\hline \multirow[t]{2}{*}{ Customer uncertainty } & Global economic environment & $\begin{array}{c}\text { Potential market size } \\
\text { Segmentation } \\
\text { Living conditions } \\
\text { Customer needs } \\
\text { Purchasing power of potential customers } \\
\text { Purchase behaviour }\end{array}$ \\
\hline & Access to export market & Alliances \\
\hline \multirow{3}{*}{ Resource uncertainty } & Access to finance & $\begin{array}{l}\text { Social networks } \\
\text { Revenue streams } \\
\text { Capital }\end{array}$ \\
\hline & Availability of skilled employees & $\begin{array}{c}\text { Skilled human resources } \\
\text { Entrepreneur's education \& experience } \\
\text { Technological resources } \\
\text { Innovation process } \\
\text { Intellectual property rights }\end{array}$ \\
\hline & Cost of $R \& D$ & $\begin{array}{l}\text { R\&D expenditures } \\
\text { Operating expenses }\end{array}$ \\
\hline
\end{tabular}

\section{Results and Discussion}

As a way to validate the proposed success prediction method, we evaluate the accuracy of our model: the dataset is split into training data $(80 \%)$ and test data $(20 \%)$. The task of the classifier is to determine the class (success or failure) depending upon the input factor values. The training data of the classifier was to label the test data output as either a positive or a negative. This task was performed on the ICT survey data set. The experiments in this research are evaluated using the standard method of accuracy, the precision/recall method, which is calculated using the predictive classification table, known as the confusion matrix. In a binary decision problem, the classifier labels as either positive (success) or negative (failure). The confusion matrix has four categories as shown in the Table 3.

Table 3. Confusion matrix.

\begin{tabular}{llll}
\hline \multirow{2}{*}{ True condition } & & \multicolumn{2}{c}{ Predicted Condition } \\
\cline { 3 - 4 } & Negative & $\begin{array}{l}T N \text { (True Negative): No. of correct } \\
\text { predictions labelled as negative }\end{array}$ & $\begin{array}{l}\text { FP (False Positive): No. of incorrect } \\
\text { predictions labelled as positive }\end{array}$ \\
\cline { 2 - 4 } & Positive & $\begin{array}{l}F N \text { (False Negative): No. of incorrect } \\
\text { predictions labelled as negative }\end{array}$ & $\begin{array}{l}\text { TP (True Positive): No. of correct } \\
\text { predictions labelled as positive }\end{array}$ \\
\hline
\end{tabular}

Precision is defined as the fraction of records predicted as positive that are actually positive. Recall reflects the probability of correctly predicting positive cases. Specificity is the probability of correctly predicting negative cases. The accuracy measures the probability of correctly predicting cases while the error rate represents the measure of incorrect predictions. The formulae for calculating these are shown in Table 4. 
Table 4. Definition of evaluation mnatrices.

\begin{tabular}{ccccc}
\hline Precision & Recall & Specificity & Accuracy & Error Rate \\
\hline$\frac{T P}{T P+F P}$ & $\frac{T P}{T P+F N}$ & $\frac{T N}{T N+F P}$ & $\frac{T P+T N}{T P+T N+F P+F N}$ & $\frac{F P+F N}{F P+F N+T P+T N}$ \\
\hline
\end{tabular}

The experiments are carried out to test the model in order to determine the accuracy. For this, we execute the proposed prediction model with both the training data and test data of both the datasets using the three classification algorithms. All three algorithms were initially trained with 198 sampling units and tested with a further 49 records using the dataset, and the results were compared to find out which algorithm performs better in predicting the pre-start-up success. The results show that all three classification algorithms achieved impressive results in the classification of attribute data. However, the naïve Bayes classifier achieved the highest accuracy and lowest error rate. The results are summarized in Table 5, which shows that the naïve Bayes classifier outperforms k-NN and SVM in predicting the outcome.

Table 5. Comparison of results-ICT survey data.

\begin{tabular}{cccccc}
\hline Classifier & Precision (\%) & Recall (\%) & Specificity (\%) & Accuracy (\%) & Error Rate (\%) \\
\hline Naive Bayes & 87.87 & 80.56 & 69.23 & 77.55 & 22.45 \\
k-NN & 82.35 & 77.78 & 53.85 & 71.43 & 28.57 \\
SVM & 87.09 & 75 & 69.23 & 73.47 & 26.53 \\
\hline
\end{tabular}

The results show that the predictor implemented with the naïve Bayes algorithm can successfully predict the probability of success with relevant data sets. The success of the start-ups can be efficiently predicted if the training data set maintained with accurate information. This is an easy, efficient and less expensive method to assess the pre-start-up success using uncertainty factors with data analysis. The result is further confirmed by changing the test data set by randomly choosing some records from the training data set.

In order to evaluate the strategic position using EFE and IFE matrix methods in order to evaluate the opportunity, two cases are used (case 1 and case 2 as shown in Tables 6 and 7). Since the importance of each source of uncertainties, the weight $w_{i}$ indicates the relative importance of the factor if a company wants to succeed in an industry. Here, we employed two domain experts from different regions to rate the factors based on their perception of external environmental situations and internal resources and capabilities. However, in reality, domain experts would be nascent entrepreneurs who would like to evaluate opportunities they have.

Table 6. External factor evaluation matrix results.

\begin{tabular}{|c|c|c|c|c|c|c|}
\hline \multicolumn{7}{|c|}{ External Factor Evaluation Matrix } \\
\hline & \multicolumn{3}{|c|}{ Case 1} & \multicolumn{3}{|c|}{ Case 2} \\
\hline Key External Factors & Weight $\left(w_{i}\right)$ & Rating * $\left(r_{i}\right)$ & $\begin{array}{l}\text { Weighted Score } \\
W_{e}=w_{i} \times r_{i}\end{array}$ & Weight $\left(w_{i}\right)$ & Rating $*\left(r_{i}\right)$ & $\begin{array}{c}\text { Weighted Score } \\
W_{e}=w_{i} \times r_{i}\end{array}$ \\
\hline Technological Developments & 0.06 & 3 & 0.18 & 0.06 & 2 & 0.12 \\
\hline Innovation speed & 0.06 & 1 & 0.06 & 0.06 & 1 & 0.06 \\
\hline Process and Methods & 0.06 & 3 & 0.18 & 0.06 & 1 & 0.06 \\
\hline Government Support & 0.06 & 4 & 0.24 & 0.06 & 1 & 0.06 \\
\hline Legal procedure & 0.04 & 4 & 0.16 & 0.04 & 2 & 0.08 \\
\hline Inflation and exchange rates & 0.02 & 3 & 0.06 & 0.02 & 2 & 0.04 \\
\hline Employment laws & 0.04 & 1 & 0.04 & 0.04 & 1 & 0.04 \\
\hline Taxation & 0.04 & 1 & 0.04 & 0.04 & 2 & 0.08 \\
\hline Economy & 0.06 & 4 & 0.24 & 0.06 & 3 & 0.18 \\
\hline
\end{tabular}


Table 6. Cont.

\begin{tabular}{|c|c|c|c|c|c|c|}
\hline \multirow[b]{3}{*}{ Key External Factors } & \multicolumn{5}{|c|}{ External Factor Evaluation Matrix } & \\
\hline & \multicolumn{3}{|c|}{ Case 1} & \multicolumn{3}{|c|}{ Case 2} \\
\hline & Weight $\left(w_{i}\right)$ & Rating $*\left(r_{i}\right)$ & $\begin{array}{c}\text { Weighted Score } \\
W_{e}=w_{i} \times r_{i}\end{array}$ & Weight $\left(w_{i}\right)$ & Rating ${ }^{*}\left(r_{i}\right)$ & $\begin{array}{c}\text { Weighted Score } \\
W_{e}=w_{i} \times r_{i}\end{array}$ \\
\hline Type of competition & 0.05 & 2 & 0.1 & 0.05 & 1 & 0.05 \\
\hline Leading Competitor & 0.05 & 2 & 0.1 & 0.05 & 1 & 0.05 \\
\hline Share of Market & 0.02 & 2 & 0.04 & 0.02 & 1 & 0.02 \\
\hline Marketing Strategy & 0.02 & 3 & 0.06 & 0.02 & 3 & 0.06 \\
\hline Potential market size & 0.04 & 2 & 0.08 & 0.04 & 1 & 0.04 \\
\hline Segmentation & 0.04 & 4 & 0.16 & 0.04 & 1 & 0.04 \\
\hline Living conditions & 0.04 & 4 & 0.16 & 0.04 & 1 & 0.04 \\
\hline Customer needs & 0.04 & 3 & 0.12 & 0.04 & 1 & 0.04 \\
\hline $\begin{array}{l}\text { Purchasing power of } \\
\text { potential customers }\end{array}$ & 0.04 & 3 & 0.12 & 0.04 & 1 & 0.04 \\
\hline Purchase behaviour & 0.04 & 4 & 0.16 & 0.04 & 4 & 0.16 \\
\hline Alliances & 0.04 & 3 & 0.12 & 0.04 & 2 & 0.08 \\
\hline Total & & & 2.71 & & & 1.48 \\
\hline
\end{tabular}

${ }^{*}$ Rating-Entered using situation analysis tool by the domain expert. Values ranging from 1 to 4.

Table 7. Internal factor evaluation matrix results.

\begin{tabular}{|c|c|c|c|c|c|c|}
\hline \multicolumn{7}{|c|}{ Internal Factor Evaluation Matrix } \\
\hline & \multicolumn{3}{|c|}{ Case 1} & \multicolumn{3}{|c|}{ Case 2} \\
\hline Key Internal Factors & Weight $\left(w_{i}\right)$ & Rating * $\left(r_{i}\right)$ & $\begin{array}{l}\text { Weighted Score } \\
W_{e}=w_{i} \times r_{i}\end{array}$ & Weight $\left(w_{i}\right)$ & Rating * $\left(r_{i}\right)$ & $\begin{array}{c}\text { Weighted Score } \\
W_{e}=w_{i} \times r_{i}\end{array}$ \\
\hline Social Networks & 0.11 & 3 & 0.33 & 0.11 & 1 & 0.11 \\
\hline Revenue streams & 0.11 & 3 & 0.33 & 0.11 & 3 & 0.33 \\
\hline Capital & 0.11 & 3 & 0.33 & 0.11 & 2 & 0.22 \\
\hline Skilled human resources & 0.09 & 4 & 0.36 & 0.09 & 2 & 0.18 \\
\hline $\begin{array}{l}\text { Entrepreneur's Education } \\
\text { and Experience }\end{array}$ & 0.09 & 3 & 0.27 & 0.09 & 3 & 0.27 \\
\hline Technological Resources & 0.09 & 4 & 0.36 & 0.09 & 1 & 0.09 \\
\hline Innovation process & 0.09 & 3 & 0.27 & 0.09 & 1 & 0.09 \\
\hline Intellectual property rights & 0.09 & 4 & 0.36 & 0.09 & 1 & 0.09 \\
\hline$R \& D$ expenditures & 0.11 & 4 & 0.44 & 0.11 & 1 & 0.11 \\
\hline Operating Expenses & 0.11 & 2 & 0.22 & 0.11 & 2 & 0.22 \\
\hline Total & & & 3.27 & & & 1.71 \\
\hline
\end{tabular}

* Rating-Entered using situation analysis tool by the domain expert. Values ranging from 1 to 4 .

Here, the most important external and internal strategic factors affecting uncertainties were identified and evaluated using EFE and IFE matrices. Then, the total weighted score of EFE and IFE matrices in both cases are calculated and plotted as I-E matrix to show the strategic position, with the EFE matrix value on $y$ axis and IFE matrix value on horizontal axis, which shows the strength of the opportunity as shown in Figure 4. In the first case, the EFE matrix outputs 2.71, signifying some growth, as any value above 2.5 is considered as probability of success. Similarly, the IFE matrix outputs 3.27 which is accepted in the literature as indicating that the resource has a higher success potential and represents a viable opportunity $[69,72]$. However, in the second case, the evaluation results with EFE score as 1.48 and IFE score as 1.71, meaning that the opportunity is not a viable opportunity.

The result shows that identified factors can explain the success and growth of a firm, to some extent, by exploiting the right opportunities. The results derived from the research state that the firm can be successful and have a favorable condition in future only if the opportunity has the right conditions and viable circumstances. The outcome of our model is aligned with the existing literature $[9,27,69]$. Thus, this opportunity evaluation model using EFE and IFE matrices to form an I-E matrix is able to correctly represent the scope of opportunity. 

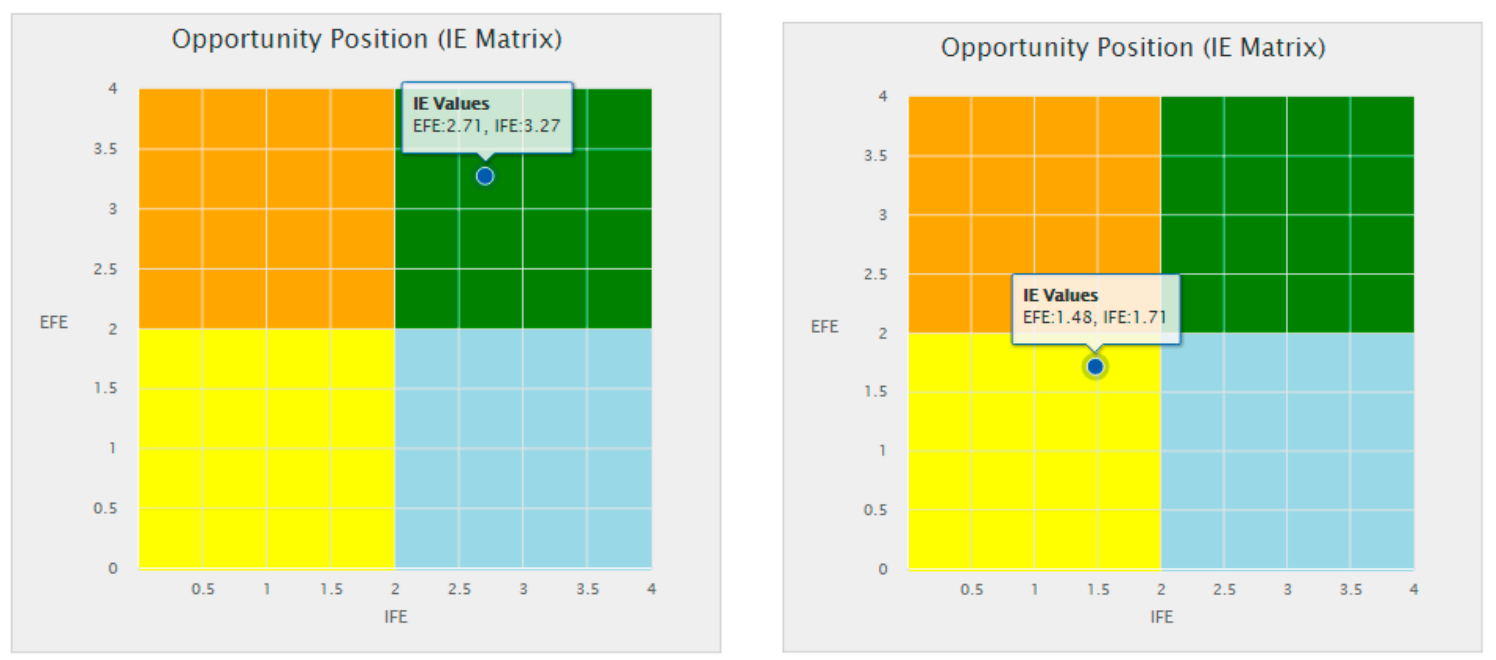

Figure 4. Strategic position using internal-external (I-E) matrix-Case 1 (Left) and Case 2 (Right).

\section{Conclusions}

Decision-making under uncertainty is fundamental to the entrepreneurial process. One reason why many professionals who have the capability to manage business are not willing to start new firms is because of the surrounding uncertainties in the environment. To address this problem, we have reviewed the literature to identify factors of uncertainties that can affect the success and growth of a new venture. We extend the types of uncertainties into sources of uncertainties and we identified uncertainty factors which act as barriers for successful sustainable technology entrepreneurship. Through the investigation of the sources of uncertainty, we identified the uncertainties related to sustainable technology entrepreneurship which provide better and clear information on the possible outcomes.

It is always necessary to make decisions in the absence of perfect information. Even though decision-making under uncertainties has been discussed in many papers, it is important to identify those uncertainties specific to technology entrepreneurship and how they can be further classified based on their source. This will help decision-makers to evaluate the environment and resources before acting on an opportunity expected to make a good and more justifiable decision. This research is an initial step towards the practicality of employing data analysis methods and techniques in predicting the probability of success of start-up ventures using uncertainty factors. The research shows that uncertainties accompanied with relevant data sets can be used to measure the probability of success of the perceived opportunity using data analysis techniques in the pre start-up phase. It helps to identify the strengths, weaknesses, opportunities, and threats associated with the perceived opportunity which will benefit nascent entrepreneurs to understand the most influential factors surrounding their potential businesses. This type of analysis enables the decision-maker to identify the uncertainties that are having a high influence on the final outcome and utilize resources efficiently. It is also interesting to see the effects of these uncertainties in each stage of the entrepreneurial process and how to manage them. These are crucial in making decisions, not only for the entrepreneurs, but also for the government and other agencies promoting sustainable technology entrepreneurship.

We conclude that our success prediction model implemented with the naïve Bayes classification algorithm is an effective tool to understand the uncertainties and correctly predicts the outcome based on the available data set. The technique will also benefit nascent entrepreneurs to predict the future and understand the most influential factors in order to gain a competitive advantage and finally become a champion as expected. This study has some limitations that must be acknowledged. In this study, a dataset from a particular industry operating in a region is used to perform the analysis. It will be interesting to enrich our model using data from different industries and from different geographical locations. Even though the accuracy of our model in predicting success is quite 
good, we are working on techniques to improve the accuracy by modifying the machine learning algorithm. Since this research focuses more on the role of uncertainties and developing an opportunity evaluation model using uncertainties, we will leave the detailed investigation on the opportunity evaluation, using personal characteristics factors in our next-step research. The method and findings discussed in this paper would benefit nascent entrepreneurs and researchers focusing on sustainable technology entrepreneurship.

Author Contributions: All authors contributed extensively to the work presented in this paper. Sarath Tomy designed the methodology, implemented the model, performed the data analysis and drafted the manuscript. Eric Pardede administered the analysis, supervised the findings of this work, gave technical support, conceptual advice and edited the manuscript. All authors provided critical feedback and helped shape the research, analysis and manuscript.

Conflicts of Interest: The authors declare no conflicts of interest.

\section{References}

1. Ardichvili, A.; Cardozo, R.; Ray, S. A theory of entrepreneurial opportunity identification and development. J. Bus. Ventur. 2003, 18, 105-123. [CrossRef]

2. Sanz-Velasco, S.A. Opportunity development as a learning process for entrepreneurs. Int. J. Entrep. Behav. Res. 2006, 12, 251-271. [CrossRef]

3. Shane, S.; Venkataraman, S. The promise of entrepreneurship as a field of research. Acad. Manag. Rev. 2000, 25, 217-226. [CrossRef]

4. Bhave, M.P. A process model of entrepreneurial venture creation. J. Bus. Ventur. 1994, 9, 223-242. [CrossRef]

5. Gentry, R.J.; Dalziel, T.; Jamison, M.A. Who do start-up firms imitate? A study of new market entries in the CLEC industry. J. Small Bus. Manag. 2013, 51, 525-538. [CrossRef]

6. Crowne, M. Why Software Product Startups Fail and What to do About It. Evolution of Software Product Development in Startup Companies. In Proceedings of the 2002 IEEE International Engineering Management Conference (IEMC '02), Cambridge, UK, 18-20 August 2002; Volume 331, pp. 338-343.

7. Butler, J.E.; Doktor, R.; Lins, F.A. Linking international entrepreneurship to uncertainty, opportunity discovery, and cognition. J. Int. Entrep. 2010, 8, 121-134. [CrossRef]

8. Zack, M.H. If managing knowledge is the solution, then what's the problem. Knowl. Manag. Bus. Model Innov. 2001, 16, 36.

9. Dollinger, M.J. Strategies and Resources; Pearson's Educational: Singapore, 2005.

10. Hoskisson, R.E.; Busenitz, L.W. Market uncertainty and learning distance in corporate entrepreneurship entry mode choice. Strat. Entrep. Creating New Mindset 2002, 151, 172.

11. Dutta, D.K.; Gwebu, K.L.; Wang, J. Personal innovativeness in technology, related knowledge and experience, and entrepreneurial intentions in emerging technology industries: A process of causation or effectuation? Int. Entrep. Manag. J. 2013, 11, 529-555. [CrossRef]

12. Brundin, E.; Gustafsson, V. Entrepreneurs' decision making under different levels of uncertainty: The role of emotions. Int. J. Entrep. Behav. Res. 2013, 19, 568-591. [CrossRef]

13. Rose, J. Software Entrepreneurship: Two Paradigms for Promoting New Information Technology Ventures; Software Innovation Aalborg University: Aalborg, Denmark, 2012; Volume 1, p. 98.

14. Lanza, A.; Passarelli, M. Technology change and dynamic entrepreneurial capabilities. J. Small Bus. Manag. 2014, 52, 427-450. [CrossRef]

15. McMullen, J.S.; Shepherd, D.A. Entrepreneurial action and the role of uncertainty in the theory of the entrepreneur. Acad. Manag. Rev. 2006, 31, 132-152. [CrossRef]

16. Milliken, F.J. Three types of perceived uncertainty about the environment: State, effect, and response uncertainty. Acad. Manag. Rev. 1987, 12, 133-143.

17. Meijer, I. Uncertainty and Entrepreneurial Action. The Role of Uncertainty in the Development of Emerging Energy Technologies; Utrecht University: Utrecht, The Netherlands, 2008; p. 220.

18. O'Brien, J.P.; Folta, T.B.; Johnson, D.R. A real options perspective on entrepreneurial entry in the face of uncertainty. Manag. Decis. Econ. 2003, 24, 515-533. [CrossRef]

19. Brun, E.; Steinar Saetre, A.; Gjelsvik, M. Classification of ambiguity in new product development projects. Eur. J. Innov. Manag. 2009, 12, 62-85. [CrossRef] 
20. Vuong, Q.H. Impacts of geographical locations and sociocultural traits on the vietnamese entrepreneurship. SpringerPlus 2016, 5, 1189. [CrossRef] [PubMed]

21. Hopp, C.; Stephan, U. The influence of socio-cultural environments on the performance of nascent entrepreneurs: Community culture, motivation, self-efficacy and start-up success. Entrep. Reg. Dev. 2012, 24, 917-945. [CrossRef]

22. Kuechle, G.; Boulu-Reshef, B.; Carr, S.D. Prediction-and control-based strategies in entrepreneurship: The role of information. Strat. Entrep. J. 2016, 10, 43-64. [CrossRef]

23. Van der Veen, M.; Wakkee, I. Understanding the entrepreneurial process. In New Firm Startups; Edward Elgar: Cheltenham, UK, 2006; pp. 27-65.

24. Wallace, S.W. Decision making under uncertainty: Is sensitivity analysis of any use? Oper. Res. 2000, 48, 20-25. [CrossRef]

25. De Koning, A.; Muzyka, D. Conceptualizing Opportunity Recognition as a Socio-Cognitive Process; Centre for Advanced Studies in Leadership: Stockholm, Sweden, 1999.

26. Baron, R.A.; Ensley, M.D. Opportunity recognition as the detection of meaningful patterns: Evidence from comparisons of novice and experienced entrepreneurs. Manag. Sci. 2006, 52, 1331-1344. [CrossRef]

27. Eriksson, J.; Li, M. Success Factors of Entrepreneurial Small and Medium Sized Enterprises in the Gnosjö Municipality. Master's Thesis, Mälardalen University, Västerås, Sweden, 2012.

28. Giardino, C.; Bajwa, S.S.; Wang, X.; Abrahamsson, P. Key Challenges in Early-Stage Software Startups. In Proceedings of the International Conference on Agile Software Development, Helsinki, Finland, 25-29 May 2015; Springer: Helsinki, Finland, 2015; pp. 52-63.

29. Keh, H.T.; Foo, M.D.; Lim, B.C. Opportunity evaluation under risky conditions: The cognitive processes of entrepreneurs. Entrep. Theory Pract. 2002, 27, 125-148. [CrossRef]

30. Sebestova, J.; Rylkova, Z.; Smysl, M. How to gain success in sme? A case study of a region in the Czech Republic. South East Eur. J. Econ. Bus. 2007, 2, 41. [CrossRef]

31. Dimov, D. Beyond the single-person, single-insight attribution in understanding entrepreneurial opportunities. Entrep. Theory Pract. 2007, 31, 713-731. [CrossRef]

32. Mazzarol, T.; Reboud, S. The strategic decision making of entrepreneurs within small high innovator firms. Int. Entrep. Manag. J. 2006, 2, 261-280. [CrossRef]

33. Paternoster, N.; Giardino, C.; Unterkalmsteiner, M.; Gorschek, T.; Abrahamsson, P. Software development in startup companies: A systematic mapping study. Inf. Softw. Technol. 2014, 56, 1200-1218. [CrossRef]

34. Kraus, S.; Kauranen, I. Strategic management and entrepreneurship: Friends or foes. Int. J. Bus. Sci. Appl. Manag. 2009, 4, 37-50.

35. Moriarty, R.T.; Kosnik, T.J. High-tech marketing: Concepts, continuity, and change. MIT Sloan Manag. Rev. $1989,30,7$.

36. Mehler-Bicher, A. Evaluating E-business Investments by Defining Profiles. In Proceedings of the 9th European Conference on IT Evaluation, Paris, France, 13-17 October 2002; pp. 317-324.

37. Yadav, N.; Swami, S.; Pal, P. High technology marketing: Conceptualization and case study. Vikalpa 2006, 31 , 57.

38. Lin, C.; Tsai, H.L.; Wu, Y.J.; Kiang, M. A fuzzy quantitative vrio-based framework for evaluating organizational activities. Manag. Decis. 2012, 50, 1396-1411. [CrossRef]

39. Stankiewicz, P. The role of risks and uncertainties in technological conflicts: Three strategies of constructing ignorance. Innov. Eur. J. Soc. Sci. Res. 2009, 22, 105-124. [CrossRef]

40. Rakesh, C. Pest analysis for micro small medium enterprises sustainability. J. Manag. Commer. 2014, 1, 18-22.

41. Spiegel, M.; Marxt, C. Defining Technology Entrepreneurship. In Proceedings of the 2011 IEEE International Conference on Industrial Engineering and Engineering Management (IEEM), Singapore, 6-9 December 2011; pp. 1623-1627.

42. Alkemade, F.; Hekkert, M.; Suurs, R. Strategic Expectations Management for Emergent Sustainable Technologies. In Proceedings of the DRUID Summer Conference on Knowledge, Innovation, and Competitiveness: Dynamics of Firms, Networks, Regions and Institutions, Copenhagen, Denmark, 18-20 June 2006; pp. 18-20.

43. Misra, K.; Memili, E.; Welsh, D.H.B.; Sarkar, S. The determinants of venture creation time: A cross-country perspective. Int. Entrep. Manag. J. 2012, 10, 253-276. [CrossRef] 
44. Shi, Y.; Xu, D.; Green, P. Software Startup Growth: The Role of Dynamic Capabilities, IT, Innovation and Customer Involvement. In Proceedings of the 19th Pacific Asia Conference on Information Systems (PACIS 2015), Singapore, 5-9 July 2015; p. 240.

45. Fenwick, C.; Howe, J.; Marshall, S.D.; Landau, I. Labour and Labour-Related Laws in Micro and Small Enterprises: Innovative Regulatory Approaches. Available online: http:/ /www.ilo.org/empent/ Publications/WCMS_093618/lang--en/index.htm (accessed on 13 February 2018).

46. Oza, N.V.; Hall, T.; Rainer, A.; Grey, S. Trust in software outsourcing relationships: An empirical investigation of indian software companies. Inf. Softw. Technol. 2006, 48, 345-354. [CrossRef]

47. Sahoo, B.K.; Nauriyal, D. Trends in and determinants of technical efficiency of software companies in India. J. Policy Model. 2014, 36, 539-561. [CrossRef]

48. Tribby, M. Reinventing the Entrepreneur: Turning Your Dream Business into a Reality; John Wiley \& Sons: Hoboken, NJ, USA, 2013.

49. Wenzel, A.M. The Entrepreneur's Guide to Market Research; ABC-CLIO: Santa Barbara, CA, USA, 2012.

50. Skinner, G.D. A study into fostering entrepreneurship in information communication technology (ICT). Int. J. Comput. Commun. 2008, 4, 108-116.

51. Ireland, R.D.; Hitt, M.A.; Sirmon, D.G. A model of strategic entrepreneurship: The construct and its dimensions. J. Manag. 2003, 29, 963-989.

52. Giarratana, M.S. The birth of a new industry: Entry by start-ups and the drivers of firm growth: The case of encryption software. Res. Policy 2004, 33, 787-806. [CrossRef]

53. Griffith, E. Why Startups Fail, According to Their Founders. Available online: http:// fortune.com/2014/09/ 25/why-startups-fail-according-to-their-founders/ (accessed on 12 August 2016).

54. Eckhardt, J.T.; Shane, S.A. Opportunities and entrepreneurship. J. Manag. 2003, 29, 333-349.

55. Ruokonen, M. Market orientation and product strategies in small internationalising software companies. J. High Technol. Manag. Res. 2008, 18, 143-156. [CrossRef]

56. Park, J.S. Opportunity recognition and product innovation in entrepreneurial hi-tech start-ups: A new perspective and supporting case study. Technovation 2005, 25, 739-752. [CrossRef]

57. Osterwalder, A.; Pigneur, Y. Business Model Generation: A Handbook for Visionaries, Game Changers, and Challengers; John Wiley \& Sons: Hoboken, NJ, USA, 2010.

58. Grégoire, D.A.; Barr, P.S.; Shepherd, D.A. Cognitive processes of opportunity recognition: The role of structural alignment. Organ. Sci. 2010, 21, 413-431. [CrossRef]

59. Baron, R.A. Opportunity recognition as pattern recognition: How entrepreneurs "connect the dots" to identify new business opportunities. Acad. Manag. Perspect. 2006, 20, 104-119. [CrossRef]

60. Shane, S. Prior knowledge and the discovery of entrepreneurial opportunities. Organ. Sci. 2000, 11, 448-469. [CrossRef]

61. Koc, T. Organizational determinants of innovation capacity in software companies. Comput. Ind. Eng. 2007, 53, 373-385. [CrossRef]

62. Fitzgerald, B.; Stol, K.-J. Continuous software engineering: A roadmap and agenda. J. Syst. Softw. 2017, 123, 176-189. [CrossRef]

63. Ng, A.W.; Macbeth, D.; Southern, G. Entrepreneurial performance of early-stage ventures: Dynamic resource management for development and growth. Int. Entrep. Manag. J. 2014, 10, 503-521. [CrossRef]

64. Ruokolainen, J.; Igel, B. The factors of making the first successful customer reference to leverage the business of start-up software company-Multiple case study in Thai software industry. Technovation 2004, 24, 673-681. [CrossRef]

65. Trimi, S.; Berbegal-Mirabent, J. Business model innovation in entrepreneurship. Int. Entrep. Manag. J. 2012, 8, 449-465. [CrossRef]

66. Tomy, S.; Pardede, E. Uncertainty Analysis and Success Prediction for Start-Ups. In Proceedings of the 5th International Conference on Innovation and Entrepreneurship (ICIE 2017), Kuala Lumpur, Malaysia, 26-27 April 2017; p. 161.

67. Xhemali, D.; Hinde, C.J.; Stone, R.G. Naive Bayes vs. Decision Trees vs. Neural Networks in the Classification of Training Web Pages; Loughborough University: Leicestershire, UK, 2009.

68. Patil, T.R.; Sherekar, S. Performance analysis of naive bayes and j48 classification algorithm for data classification. Int. J. Comput. Sci. Appl. 2013, 6, 256-261. 
69. Capps, C.J., III; Glissmeyer, M.D. Extending the competitive profile matrix using internal factor evaluation and external factor evaluation matrix concepts. J. Appl. Bus. Res. 2012, 28, 1059-1062. [CrossRef]

70. Cassidy, C.M.; Glissmeyer, M.D.; Capps, C.J., III. Mapping an internal-external (IE) matrix using traditional and extended matrix concepts. J. Appl. Bus. Res. 2013, 29, 1523. [CrossRef]

71. Lisiński, M.; Šaruckij, M. Principles of the application of strategic planning methods. J. Bus. Econ. Manag. 2006, 7, 37-43.

72. Ommani, A.R. Strengths, weaknesses, opportunities and threats (SWOT) analysis for farming system businesses management: Case of wheat farmers of Shadervan District, Shoushtar Township, Iran. Afr. J. Bus. Manag. 2011, 5, 9448-9454.

73. Haghayegh, R.A.S.; Foomani, A.F.; Chaboki, M.H. An Algorithm for Integrating Strategic Planning in Holding Companies. In Proceedings of the 3rd International Conference on New Directions in Business, Management, Finance and Economics (ICNDBM 2015), Istanbul, Turkey, 6 November 2015.

74. Ghazinoory, S.; Esmail Zadeh, A.; Kheirkhah, A.S. Application of fuzzy calculations for improving portfolio matrices. Inf. Sci. 2010, 180, 1582-1590. [CrossRef]

75. Tomy, S.; Pardede, E. Opportunity evaluation using uncertainties in software entrepreneurship. Entrep. Res. J. 2017. [CrossRef]

76. Lodato, M.W. A Handbook for Managing Strategic Processes; AuthorHouse: Bloomington, IN, USA, 2014; Volume 1, p. 348.

77. Nourbakhsh, S.Z.; Shahba, S.; Mozafari, M. Using SWOT analysis and QSPM matrix for developing and evaluating strategies of ecotourism. Casp. J. Appl. Sci. Res. 2013, 2, 116-125.

78. Department of Economic Development, Jobs, Transport and Resources, Victoria. Victorian ICT Industry Statistics Survey; Department of Economic Development, Jobs, Transport and Resources, Victoria: Melbourne, Australia, 2013.

(C) 2018 by the authors. Licensee MDPI, Basel, Switzerland. This article is an open access article distributed under the terms and conditions of the Creative Commons Attribution (CC BY) license (http:/ / creativecommons.org/licenses/by/4.0/). 